\title{
False recency and false fame of faces in young adulthood and old age
}

\author{
JAMES C. BARTLETT, LAURA STRATER, and ANNETTE FULTON \\ University of Texas at Dallas, Richardson, Texas
}

\begin{abstract}
Studies of age differences in face recognition have shown age-related increases in false-alarm errors: elderly persons exceed young adults in judging new faces to be old. To distinguish among theoretical accounts of this finding, we compared young and elderly subjects in two recognition tasks: (1) that of judging whether faces were recent or nonrecent, and (2) that of judging whether faces were famous or nonfamous. The major independent variable was prior presentation of facesincluding nonrecent and nonfamous foils-1 week before the test. False recent judgments in response to nonrecent faces and false famous judgments in response to nonfamous faces were higher among the elderly. Moreover, these age-related differences in false-alarm rates were larger for faces viewed 1 week previously than for entirely new faces. The findings suggest that, compared to young adults, older individuals rely relatively more on perceived familiarity, and relatively less on recollection of context, in making recognition decisions.
\end{abstract}

A critical function of long-term memory is the recognition of persons, often by their faces. The ecological importance of face recognition extends across the lifespan, and the early development of face recognition has been actively researched (see Flin \& Dziurawiec, 1989). Yet the relation of aging to face recognition has received but scant attention. The available studies suggest near ageinvariance in correct old judgments in response to previously viewed faces (i.e., hit rates). However, elderly persons exceed young adults in erroneous old judgments in response to new faces (i.e., false-alarm rates; see, e.g., Bartlett, Leslie, Tubbs, \& Fulton, 1989). This effect generalizes across levels of educational background of subjects (Smith \& Winograd, 1978), incidental as opposed to intentional encoding (Smith \& Winograd, 1978), changes in retention interval (Ferris, Crook, Clark, McCarthy, \& Rae, 1980), and more or less naturalistic modes of face presentation (Bartlett \& Leslie, 1986). ${ }^{1}$

Our goal in this study was to explore possible reasons for the age-related differences in false recognition of faces. A better understanding of these age-related differences would speak to theories of aging and memory, and also to models of face recognition. Despite the emergence of many such models (Bruce, 1988), the nature and causes of false recognitions of new faces are poorly understood (Davies, Shepherd, \& Ellis, 1979; Goldstein, Stephenson, \& Chance, 1977). In addition, a better understanding of

This project was supported by National Institute on Aging Grant 1-RO1AG07798. We thank W. Jay Dowling, Alice O'Toole, and Hervé Abdi for many helpful discussions, Gillian Cohen, Margaret Intons-Peterson, and Daniel Schacter for their comments on an earlier draft of this article, and Cheryl Pace for help with Experiment 2. Correspondence should be addressed to James Bartlett, Program in Human Development and Communication Sciences, University of Texas at Dallas, Box 830688 , Richardson, TX 75080-0688 (or KZAK@UTDALLAS.BITNET) age-related differences in face recognition would suggest new techniques for reducing false alarms by older individuals in eyewitness identification and other "real-life" situations where such mistakes are frequent (List, 1986; Yarmey, 1984; Young, Hay, \& Ellis, 1985).

Age-related increases in false-alarm errors are not unique to face recognition; such age-related increases have been found in several studies of recognition memory for verbal stimuli (see, e.g., Hess, 1984; Hess \& Higgins, 1983; Rankin \& Kausler, 1979; Reder, Wible, \& Martin, 1986; Smith, 1975), as well as a study of recognition of actions (Cohen \& Faulkner, 1989). However, such studies of recognition of nonfacial stimuli, both verbal and nonverbal, have produced a variety of discrepant results, including: (1) significant age differences in hits, but not in false alarms (Light \& Anderson, 1983; Park \& Puglisi, 1985); (2) age differences of varying size and/or pattern across conditions and experiments (Park, Puglisi, \& Smith, 1986; Rabinowitz, 1984); and (3) no significant age differences at all (e.g., Craik \& McDowd, 1987; Harkins, Chapman, \& Eisdorfer, 1979). The relative stability of the findings on face recognition makes an ideal domain to explore why the elderly, in some situations, have high rates of false alarms.

In order to generate some alternative hypotheses for age-related differences in false recognitions of new faces, we used a widely accepted model of face recognition (Bruce \& Young, 1986; see also Bruce, 1988; Young \& Ellis, 1989) as a conceptual framework. Although the Bruce and Young model is not without competitors, it has a strong family resemblance to most of these competitors, and it is supported by a wide variety of evidence. Its most basic claim is that face recognition involves two retrieval processes coupled with a cognitive system that weighs the products of these two retrieval processes to make recognition decisions. The first retrieval process is that of de- 
tection of resemblance between a perceptually available face and face-recognition units in memory. This resemblance (familiarity) process can be followed in some cases by recollection of semantic and contextual information via person identity nodes. The cognitive system weighs the resemblance information, along with contextual and semantic information (if any), to recognize and possibly identify a face. This idea of two (or more) retrieval processes interacting with a flexible decision-making system is broadly consistent with dual- and multiprocess conceptions of recognition memory for verbal materials (see, e.g., Gillund \& Shiffrin, 1984; Jacoby, Kelly, \& Dywan, 1989; Mandler, 1980; Reder et al., 1986; Tulving, 1983), as well as pictures (Bartlett, Gernsbacher, \& Till, 1987).

The Bruce and Young (1986) model suggests three different hypotheses for the age-related increase in false alarms in response to new faces. The first is a compensation hypothesis, which holds that older individuals suffer deficits in encoding and/or retrieval that impair their ability to recognize faces. To compensate for these processing deficits, the cognitive systems of older adults are biased to signal that a face is familiar even when resemblance is relatively slight. Such a compensation strategy on the part of older subjects would enhance their rate of hits and would tend to attenuate age differences in hits. However, the price to be paid for using this strategy would be a high rate of false-alarm errors, in comparison with the performance of young adults.

The compensation hypothesis makes an obvious prediction for signal detection measures of discrimination and criterion. Older subjects should show reduced discrimination between old and new faces, as well as looser criteria for making old judgments. In support of this prediction, both Smith and Winograd (1978) and Bartlett et al . (1989) found age-related decreases in a discrimination measure $\left(d^{\prime}\right)$, as well as in a criterion measure $(\beta$ and $C$ scores, respectively). Ferris et al. (1980) obtained the same pattern, though the age difference in criterion was not statistically significant. Despite this generally positive evidence, the compensation hypothesis is disturbingly post hoc; it does not explain why older individuals would favor a loosening rather than a tightening of criteria as a compensating strategy (cf. Cohen \& Faulkner, 1989, pp. 13-14). Of course, a loosening of criteria would reduce the occurrence of recognition failures (misses), which are obviously embarrassing. However, a tightening of criteria would reduce the occurrence of false recognitions, which can also be embarrassing.

The second hypothesis proposes age differences in the perception of the resemblance (familiarity) of faces: There is evidence that even entirely new faces evoke signals of resemblance (or perceived familiarity) from facerecognition units (Bartlett, Hurry, \& Thorley, 1984; Young et al., 1985). Given this evidence, a plausible hypothesis is that new faces on a test evoke stronger signals of resemblance in older adults than in younger adults. The claim is not that older subjects have adopted the strategy of making old judgments on the basis of low resem- blance levels (the compensation hypothesis). Instead, older subjects simply experience more resemblance in response to new faces than do young adults.

A resemblance hypothesis is intuitively plausible on the basis of at least two speculative arguments. First, older individuals, who have lived longer and encountered more people, may have more representations of faces (i.e., facerecognition units) stored in long-term memory. Partial matches with these face representations might increase the perceived resemblance of (nominally) new faces. Second, older adults may form less distinctive representations of faces. For example, there might be age-related deficits in finding and encoding the most discriminating facial features into face-recognition units (Winograd, 1981), or simply age-related reductions in the number of features stored. In either case, entirely new faces would be relatively more likely to match some existing representation in memory. This would lead to increased false alarms (cf. Snodgrass \& Corwin, 1988).

The third hypothesis derives from the claim of the Bruce and Young (1986) model that the recollection of contextual and semantic information supports face-recognition judgments. With stimuli such as faces, which are highly homogenous because they all share the same global configuration (Diamond \& Carey, 1986), many new items in a recognition test might produce good matches with face-recognition units (in young as well as elderly adults). This would lead, at least in some cases, to strong signals of resemblance, which might increase the probability of false-alarm errors. However, if there is successful recollection of semantic and/or contextual information, such errors might be minimized. For example, a subject in a study might encounter a face that resembles that of someone seen frequently on the street. This face might seem familiar, but if the subject can remember the context of this face (the street), he or she can reject the face as not being from a certain recent event (e.g., an input list or simulated crime). The implication for aging and memory is clear: Age-related increases in false-alarm errors might be explained if (many) elderly persons base recognition judgments relatively more on perceived resemblance, and relatively less on retrieval of contextual information, in comparison with younger persons.

In summary, the Bruce and Young (1986) model of face recognition (and other models also) suggests three interpretations of age-related increases in false recognitions of new faces. First, a compensation hypothesis claims that elderly subjects have relaxed their criteria for recognizing faces as a means of compensating for face-processing deficits. Second, a resemblance hypothesis proposes age-related increases in the level of resemblance (perceived familiarity) evoked by new faces. Third, a context-recollection hypothesis claims that there are age-related decreases in the recollection of context and semantic information, and, therefore, that there are age-related increases in using resemblance (familiarity) to make recognition judgments.

In order to test these three interpretations, we conducted two experiments that tapped two different types of face- 
Table 1

Sequence of Events in Experiments 1 and 2
1. First input list of Experiment 1 (12 min)
1. Second input list of Experiment 1 (12 $\mathrm{min})$
2. Tests of vocabulary, paired-associates, and
2. Visual acuity test $(5 \mathrm{~min})$ paragraph recall $(30 \mathrm{~min})$
3. Input list of Experiment 2 (10 min)
3. Fame recognition test of Experiment 2 (20 min)
4. Recency recognition test of Experiment 1 (18 min)

Note-Time between sessions $=1$ week. Times in parentheses include time for instructions.

recognition memory. The two studies were conducted on the same subjects and were interleaved together as is illustrated in Table 1. The chief manipulation in each study was whether and how often subjects saw the lure faces before the start of the recognition test. On the assumption that the familiarity of faces increases as a function of their prior presentations, the context-recollection hypothesis makes an interesting prediction: The number of prior presentations of lures should be positively related to false-alarm errors, and this effect should be stronger in an elderly group than in a young-adult group. In consequence, the age-related increase in false-alarm errors should be greater for faces presented more often. Neither the compensation hypothesis nor the resemblance hypothesis can make this prediction of a prior presentation $x$ age interaction.

\section{EXPERIMENT 1}

Adapting a procedure used by Huppert and Piercy (1978; see also Bartlett et al., 1987; Craik, 1989), we had our young and older subjects view two lists of faces, with a 1-week interval between the two lists. Each of the lists included 24 faces, 12 presented twice and 12 presented only once. About 30 min after the second input list, the subjects took a test that included the $\mathbf{4 8}$ previously viewed faces, along with 24 new faces. The task was simply to judge each item as seen today, seen last week, or new.

Of primary interest were the proportions of erroneous today judgments (i.e., false-alarm errors) of nonrecent faces presented two times, one time, or not at all before the test. An obvious expectation based on prior research was that false-alarm rates would show an age-related increase. The critical issue was how prior presentations of the nonrecent faces would influence the size of this agerelated increase.

\section{Method}

Subjects. The 19 young subjects included 15 female and 4 male undergraduate students in psychology at the University of Texas at Dallas. Their ages ranged from 21 to 37 years ( $M=28$ years), and they participated as one means of fulfilling a course requirement. The 20 elderly subjects included 16 females and 4 males recruited from church groups and residential communities for the elderly in Dallas. All but 1 of the elderly were high school graduates, and 15 had completed 1 or more years of college ( 5 were college graduates). Their ages ranged from 60 to 82 years $(M=72$ years), and they participated for pay $(\$ 20)$. Scores on a vocabulary test (the second half of the Wechsler Adult Intelligence Scale) were higher among the elderly [Ms $=21.7$ and 28.5 out of 40 , with $S D$ s of 4.2 and 6.5 , for young and elderly subjects, respectively; $t(37)=3.86, p<.005$ ]. Visual acuity (tested by Snellen chart) was $20 / 50$ or better in the best eye (only 1 young and 2 elderly subjects scored worse than 20/30). ${ }^{2}$

Materials. The materials consisted of five different photographs of each of 72 faces, including 34 male faces and 38 female faces, and 24 faces in each of three age groups-young, middle-aged, and elderly (mean rated ages $=29,45$, and 65 years, respectively). The five different photographs of each face included a left- and a right-profile view, a left- and a right-three-quarters view, and a frontal view, with three of these views showing a smiling expression and two views showing a neutral expression, or vice versa. All photographs were made with jewelry removed and clothing obscured by a sheet draped around the shoulders.

The photographs, which were originally $35-\mathrm{mm}$ transparencies, were recorded on an optical disk using a Tamron Fotovix video processor coupled to a Panasonic TQ-2026F optical memory disk player/recorder (single-write/multiple-read) upgraded from VHS to Super-VHS quality. The player/recorder was interfaced with a small computer for controlling sequencing and timing of images in the production of input and test lists. These lists were recorded onto Super-VHS videotapes in black and white and presented to the subjects via high quality 21 " Super-VHS monitors. This allowed for comfortable viewing in fully lighted rooms at distances of 5-7 ft.

Subjects received two input lists. Each of these lists contained 24 faces, including 8 young, 8 middle-aged, and 8 elderly faces. Each input face was shown in four successive views with alternating expressions (smile-neutral-smile-neutral or neutral-smile-neutralsmile), beginning with the left-profile view, followed by a left-threequarters view and then a frontal view or a frontal view and then a right-three-quarters view and, finally, a right-profile view (the three-quarters view that was not shown at input was used subsequently in the recognition test). This multiview procedure is more naturalistic than the standard single-view procedure, and it minimizes age differences in old/new recognition (Bartlett \& Leslie, 1986).

Half (12) of the faces in each input list were shown just once, but the remainder were shown twice with 4 faces (i.e., 16 pictures) between the presentations. The ordering of faces in each list was random, with the constraint that the 1st presentation of a twicepresented face could occur no later than Serial Position 31 (so that the 2 nd presentation would be no later than Position 36). A filler face appeared at each end of each list, making 38 face presentations in all (i.e., 1 presentation of each of 12 faces, 2 presentations of each of 12 faces, and 1 presentation of each of 2 filler faces).

The recognition test contained 72 faces, randomly ordered, including 24 faces from a subject's first list, 24 faces from a subject's second list, and 24 new faces. Each test stimulus was a single photograph depicting a left- or right-three-quarters view with either a smiling or a neutral expression. Faces shown at input were always tested in the three-quarters view not seen at input and with the facial expression not seen with that view. Thus, each of the faces on each input list was initially studied in four different views and was tested in a fifth view not seen before. This procedure eliminated the possible contribution of pictorial features (e.g., smudges 
or streaks on the images) to recognition judgments (Hay \& Young, 1982).

For counterbalancing purposes, six different subgroups of 3-4 subjects (within each age group) received different versions of the two input lists. The result was that each face served (1) approximately equally often as a member of a subject's first list, as a member of a subject's second list, and as a new item in the recognition test, and (2) approximately equally often as a once-presented input face and as a twice-presented input face.

Procedure and Design. Experimental sessions included 1-4 subjects. At the start of the first session, the subjects were told that they would see a list of faces, with each face shown in four different poses. They were told that though none of the faces were famous, even nonfamous faces can sometimes seem familiar, and that the input task was to rate each face for perceived familiarity on a 6 -point scale ( $1=$ not at all familiar and $6=$ very familiar). The instructions also stated that some faces would be repeated, and that subjects should circle the serial position numbers of all such repeat faces. A familiarity rating was unnecessary in such cases.

After hearing these instructions, the subjects viewed the first input list. Presentation time was $12 \mathrm{sec}$ per face (4 pictures at $3 \mathrm{sec}$ per picture), with a $3-\mathrm{sec}$ inter-face interval, or about $9.5 \mathrm{~min}$ for the entire list.

To gain some information on how our subjects might perform on standard verbal memory tasks, the first input list in Session 1 was followed by a 30-min phase of verbal-memory tasks that included tests for paragraph and paired-associates recall taken from the Guild Memory Test (Gilbert, Levee, \& Catalano, 1974), as well as the vocabulary test (second half of the WAIS test). The sequence of events was as follows: (1) oral presentation of Paragraph 1 (about $25 \mathrm{sec}$ ), followed by written recall of Paragraph 1 and re-presentation of the paragraph; (2) oral presentation of a 10-item paired-associates list (presentation rate $=8 \mathrm{sec}$ per pair), followed by written recall of the paired-associates list; (3) delayed recall of Paragraph 1; (4) delayed recall of the paired-associates list; (5) oral presentation of Paragraph 2 (about $25 \mathrm{sec}$ ), followed by written recall of Paragraph 2 and re-presentation of the paragraph; (6) the 10-min vocabulary test (see Subjects section); and (7) delayed recall of Paragraph 2. Paragraph and paired-associates testing were both self-paced; the experimenter waited until all subjects in a session indicated that they were ready before moving to the next test item or task (at least $10 \mathrm{sec}$ were allowed for recall of each paired-associates item). The verbal-memory phase was followed by the input list for Experiment 2 (see below), which took about $10 \mathrm{~min}$. The entire first session lasted $55 \mathrm{~min}$.

The second session (1 week later) began with the second input list. The instructions from Session 1 were repeated, followed by the list itself. This second list was structured in the same way as the first, though all of the faces were new.

After presentation of the second input list, Session 2 continued with testing for visual acuity (with the Snellen chart), plus the recognition phase for Experiment 2. After completion of these two tasks, which, including the instructions, took $25 \mathrm{~min}$, the recognition test for Experiment 1 was given. The subjects were told that they would see a set of faces, including some seen earlier in the session and others seen 1 week before. Their task was to judge each face as seen today, seen last week, or new. They responded by marking appropriate columns on the test forms provided. The 72 test pictures were presented for $7 \mathrm{sec}$ each, with a 3-sec interstimulus interval. The test required $12 \mathrm{~min}$ to complete; the entire second session lasted $55 \mathrm{~min}$.

\section{Results}

Familiarity and recognition judgments at input. During presentation of each of the two input lists, subjects judged whether faces were repeated and made ratings for the level of perceived familiarity of faces they judged to be nonrepeated. Turning first to repeated judgments, Table 2 shows that correct repeated judgments in response to repeated input items were at or near the ceiling in the first input list, though there was an age-related decrease in the second input list. False repeated judgments in response to nonrepeated faces showed an age-related increase in both input lists. In contrast, there were no significant age-related differences in the mean familiarity of nonrepeated items.

Today, last-week, and new judgments at test. As an initial approach to the data, we computed mean proportions of each test response to items shown in the second input list (today items), items shown in the first input list (last-week items), and items not shown until the test (new items). Figure 1 displays these data.

Above-chance performance was revealed by the fact that each type of judgment was substantially more frequent in response to the appropriate class of items than to the inappropriate class of items (e.g., today judgments were more frequent in response to today items than to last-week and new items). However, the size of this effect was consistently larger among the younger subjects, suggesting age differences in accuracy. Age differences in bias were also apparent: The young exceeded the elderly subjects in the overall proportion of last-week judgments $(M \mathrm{~s}=$ .39 and .19 , respectively), whereas the young fell below the elderly subjects in proportions of today and new judgments $(M s=.25$ and .36 , respectively, for today judgments, and .36 and .45 , respectively, for new judgments).

To assess the significance of the age-related differences, the data from each of the three response types were subjected to an analysis of variance (ANOVA) with age group and item type as factors. All three ANOVAs showed main effects for age $\left[F_{\mathrm{S}}(1,37)=8.89,56.4\right.$, and $4.48 ; M S_{\mathrm{e}} \mathrm{S}=$ $.041, .021$, and .049 , for today, last-week, and new judg-

Table 2

Mean Proportions of Repeated Judgments in Response to Repeated Faces (Hit Rates) and Nonrepeated Faces (False-Alarm Rates), and Mean Familiarity Ratings for Responses to Faces in the Input Phases of Experiments 1 and 2

\begin{tabular}{|c|c|c|c|c|c|c|c|c|c|c|c|c|c|c|c|c|c|c|}
\hline \multirow[b]{4}{*}{ Age Group } & \multicolumn{12}{|c|}{ Experiment 1} & \multirow{2}{*}{\multicolumn{6}{|c|}{$\begin{array}{c}\text { Experiment } 2 \\
\text { First Session }\end{array}$}} \\
\hline & \multicolumn{6}{|c|}{ First Session } & \multicolumn{6}{|c|}{ Second Session } & & & & & & \\
\hline & \multicolumn{2}{|c|}{ Hit Rate } & \multicolumn{2}{|c|}{$\begin{array}{l}\text { False-Alarm } \\
\text { Rate }\end{array}$} & \multicolumn{2}{|c|}{$\begin{array}{l}\text { Familiarity } \\
\text { Rating }\end{array}$} & \multicolumn{2}{|c|}{ Hit Rate } & \multicolumn{2}{|c|}{$\begin{array}{l}\text { False-Alarm } \\
\text { Rate }\end{array}$} & \multicolumn{2}{|c|}{$\begin{array}{c}\text { Familiarity } \\
\text { Rating } \\
\end{array}$} & \multicolumn{2}{|c|}{ Hit Rate } & \multicolumn{2}{|c|}{$\begin{array}{c}\text { False-Alarm } \\
\text { Rate }\end{array}$} & \multicolumn{2}{|c|}{$\begin{array}{l}\text { Familiarity } \\
\text { Rating }\end{array}$} \\
\hline & $M$ & $S D$ & $M$ & $S D$ & $M$ & $S D$ & $M$ & $S D$ & $M$ & $S D$ & $M$ & $S D$ & $M$ & $S D$ & $M$ & $S D$ & $M$ & $S D$ \\
\hline Young & .99 & .03 & .02 & .03 & 2.2 & .74 & .99 & .03 & .04 & .05 & 2.2 & .82 & .98 & .04 & .04 & .04 & 1.9 & .57 \\
\hline Elderly & .97 & .08 & $.10^{*}$ & .10 & 1.9 & 1.2 & $.89^{*}$ & .16 & $.15^{*}$ & .11 & 1.8 & .94 & .95 & .10 & $.10^{*}$ & .11 & 1.9 & 1.1 \\
\hline
\end{tabular}

Note-Familiarity ratings were on a 6-point scale, where $1=$ entirely unfamiliar. ${ }^{*}$ Age difference gave $p<.05$ by $t$ test. 


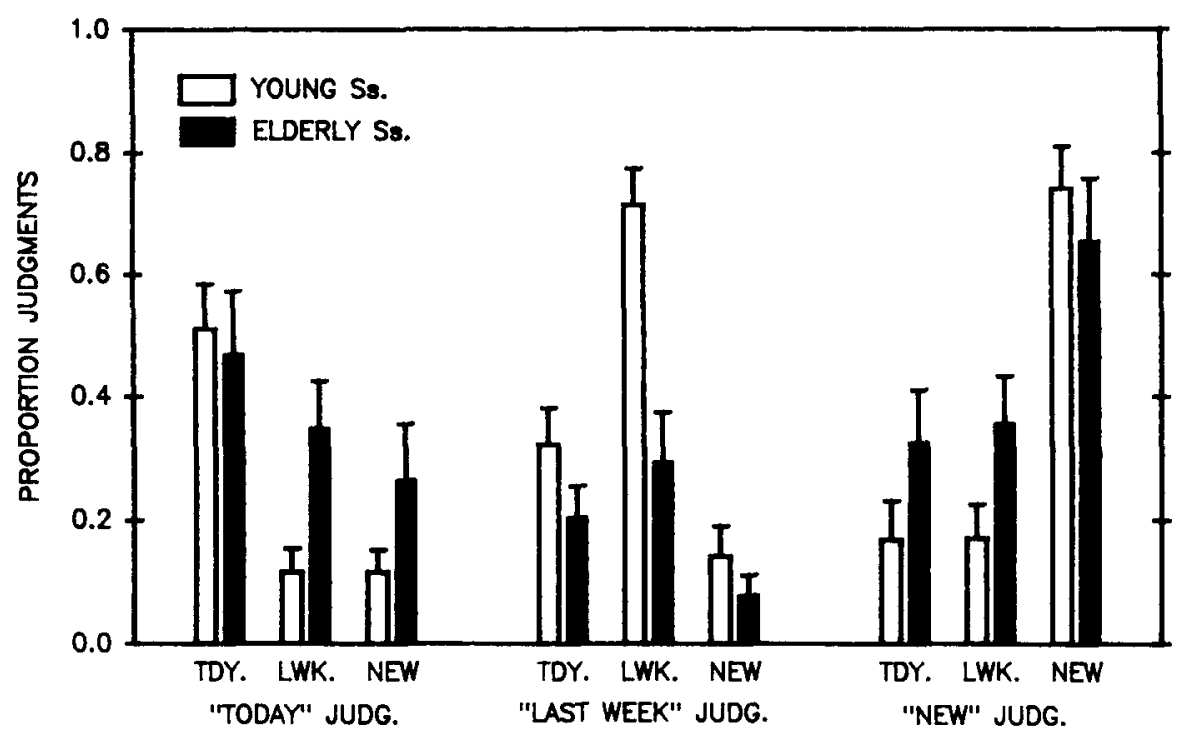

Figure 1. Proportions of today, last-week and new judgments in response to today, last-week, and new items made by young and elderly subjects in Experiment 1 . Vertical lines show the upward tails of the $95 \%$ confidence intervals.

ments, respectively]. Moreover, all three ANOVAs revealed main effects for item type $\left[F_{\mathrm{S}}(2,74)=63.8,139.3\right.$, and 178.6; $M S_{\mathrm{e}} \mathrm{s}=.016, .011, .014$, respectively], as well as significant item-type $\times$ age interactions $[F \mathrm{~s}(2,74)=$ $12.0,32.9$, and 15.2; $M S_{\mathrm{e}} \mathrm{s}=.016, .011$, and .014 , respectively]. The alpha level here and in all subsequent tests was set at .05 .

Although we did not predict the pattern of last-week or new judgments, the today judgments replicated prior findings, in that hit rates (to today items) varied only slightly (and nonsignificantly) with age, whereas falsealarm rates (to last-week and new items) showed clear age-related increases $[t \mathrm{~s}(37)=5.72$ and 3.13 , respectively]. We will henceforth focus on these today judgment data.

Today judgments. Figure 2 displays the proportions of today judgments as a function of age and prior presentations. The lower two functions show mean proportions of false today judgments given zero, one, or two presentations in the first (nonrecent) list. An ANOVA of these false-alarm rates showed a robust main effect of age $\left[F(1,37)=30.5, M S_{\mathrm{e}}=.121\right]$ and a marginal prior presentations $\times$ age interaction $\left[F(2,74)=2.44, M S_{\mathrm{e}}=\right.$ $.048, .05<p<.10]$. The interaction was reliable by conventional standards in a contrast of zero-presented with twice-presented items $\left[F(1,37)=4.44, M S_{e}=.052\right]$, though not in a contrast of zero- and once-presented items or of once- and twice-presented items. The $\omega^{2}$ measure showed that the percentage of the between-subjects variance accounted for by subject age rose from entirely new items $(18 \%)$ to once-presented-nonrecent items $(27 \%)$ to twice-presented-nonrecent items $(40 \%){ }^{3}$

An alternative description of Figure 2 is that increments in the number of prior presentations caused increases in both false today judgments and correct today judgments, but primarily in the elderly group. This pattern was examined in a second ANOVA of proportions of today judgments for recent and nonrecent items (i.e., hit and falsealarm rates) given one versus two presentations at input (zero-presented items were dropped). There was a main effect of recency, which reflected the fact that hit and falsealarm rates differed $\left[F(1,37)=81.9, M S_{\mathrm{e}}=.094\right]$. There were also main effects of age $\left[F(1,37)=4.92, M S_{\mathrm{e}}=\right.$ $.220]$ and prior presentations $\left[F(1,37)=25.2, M S_{\mathrm{e}}=\right.$ $.038]$, as well as significant interactions between age and recency $\left[F(1,37)=23.3, M S_{\mathrm{c}}=.094\right]$, presentations and recency $\left[F(1,37)=6.49, M S_{\mathrm{e}}=.075\right]$, and presentations and age $\left[F(1,37)=5.90, M S_{\mathrm{e}}=.038\right]$. The interactions

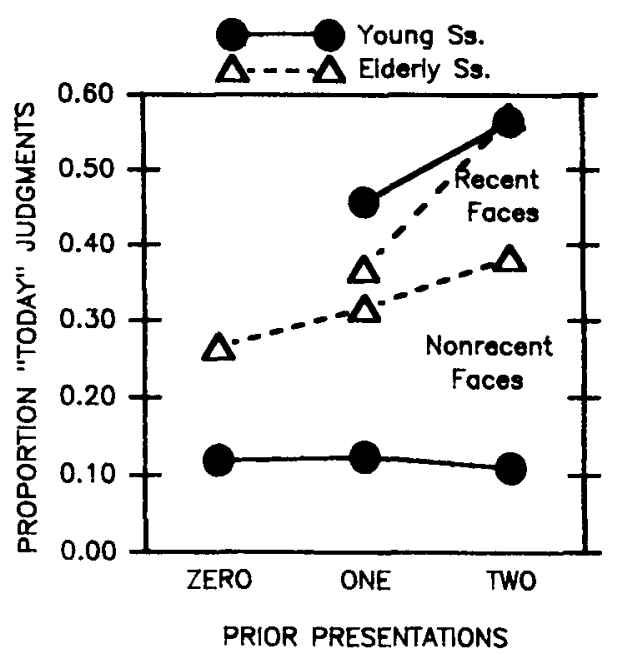

Figure 2. Proportions of today judgments in response to recent faces (hits) and nonrecent faces (false alarms), as a function of number of prior presentations in the young and elderly subject groups of Experiment 1. 
involving the recency variable suggest that the accuracy of performance (the hit rate minus false-alarm rate difference) was generally higher for twice-presented items than for once-presented items and for younger subjects than for older subjects. The presentations $\times$ age interaction supports our observation that while today judgments were higher for twice-presented items than for once-presented items, this effect was stronger in the older age group. Indeed, ANOVAs performed on each age group separately showed a significant main effect of presentations in the elderly group $\left[F(1,19)=31.6, M S_{\mathrm{e}}=.035, p<.0001\right]$, though not in the young-adult group $[F(1,18)=2.95$, $\left.M S_{\mathrm{e}}=.043, p>.10\right]$.

Signal detection analysis of today judgments. A useful perspective on the today judgment data is gained through an analysis of discrimination versus criterion effects. Figure 3 displays mean $d^{\prime}$ scores (for discrimination accuracy) and mean $C$ scores (for criterion levels) derived from correct today judgments (hit rates) in response to items from the second (recent) input list, and erroneous today judgments (false-alarm rates) in response to items from the first (nonrecent) input list. The means are broken down by prior presentations (one vs. two) as well as subject age. ${ }^{4}$

The $d^{\prime}$ values were increased by repetition, and they were higher for young than for elderly adults. In contrast, the corresponding $C$ scores (for bias) showed an interactive pattern in which repetition produced more lax criteria, but primarily among the elderly subjects. In support of these observations, an ANOVA performed on the $d^{\prime}$ scores showed a main effect of prior presentations $\left[F(1,37)=7.15, M S_{\mathrm{e}}=1.07\right]$ in addition to an effect of age $\left[F(1,37)=31.9, M S_{\mathrm{e}}=1.05\right]$, with no interaction. In contrast, an ANOVA on the $C$ scores showed not only main effects of presentations and age $[F(1,37)=35.9$ and 5.27, $M S_{\mathrm{e}}=.113$ and .468 , respectively], but also a significant presentations $\times$ age interaction $[F(1,37)=8.51$,
$\left.M S_{e}=.113\right]$. Subsidiary ANOVAs showed only a marginal effect of prior presentations on $C$ scores in the youngadult group $\left[F(1,18)=3.77, M S_{c}=.138, .05<p<\right.$ $.10]$, but there was a robust effect in the elderly group $\left[F(1,19)=51.4, M S_{\mathrm{e}}=.089, p<.0001\right]$. We conclude from these data that the elderly were less accurate in their recency judgments, and that they also differed qualitatively from the young-adult subjects in showing a significant effect of repetition on criterion.

Relations of age differences to verbal-memory performance. The verbal-memory testing in Session 1 (Table 1) revealed marked age differences. Averaging immediate and delayed-test scores, paired-associates recall scores were 16.6 versus 7.6 (out of 20 ) in the young versus the elderly groups $\left(S D_{\mathrm{S}}=2.8\right.$ and 4.0 , respectively). Paragraph recall scores averaged 29.6 versus 21.6 (out of 43 ) in the young as opposed to the elderly ( $S D s=2.4$ and 4.4 , respectively). ${ }^{5}$

The low verbal-memory scores of the elderly subjects raised the question of whether age differences in verbalmemory ability might help explain age differences in face recognition. To address this issue, we computed correlations between verbal-memory scores and $d^{\prime}$ and $C$ scores for once- and twice-presented items. As is shown in Table 3 , the verbal-memory scores were consistently negatively correlated with $d^{\prime}$ scores for once-presented items, but they were more often positively correlated with $d^{\prime}$ scores for twice-presented items. The pattern was consistent across both age groups, and it was supported most strongly when the age groups were combined and the factor of age was statistically removed. We do not attempt to explain these correlations, but note that they differed qualitatively from the correlations with age. Age was negatively correlated with $d^{\prime}$ scores for once- and twicepresented items $(r s=-.70$ and -.44 , respectively, $d f \mathrm{~s}=$ 37 ). We also note that the $C$ scores showed no significant correlations with paired-associates recall or paragraph

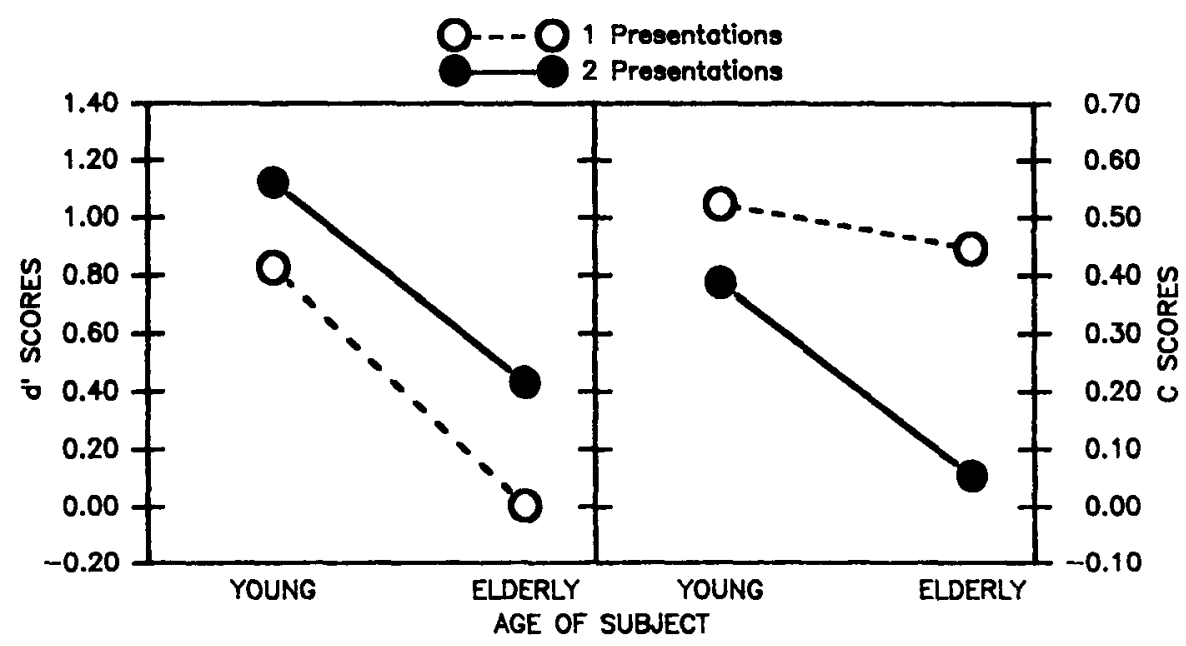

Figure 3. $d^{\prime}$ scores (for recency-discrimination accuracy) and $C$ scores (for recognition criterion) for once- and twice-presented items in the young and elderly subject groups of Experiment 1 (lower $C$ scores reflect more lax criteria). 
Table 3

Pearson Product-Moment Correlations between Verbal-Memory Measures and $d^{\prime}$ and $C$ Scores for Recency Discrimination and Bias for Once- and Twice-Presented Faces in Experiment 1

\begin{tabular}{|c|c|c|c|c|c|c|c|c|}
\hline \multirow[b]{3}{*}{ Age Group } & \multicolumn{4}{|c|}{ Paired-Associates Recall } & \multicolumn{4}{|c|}{ Paragraph Recall } \\
\hline & \multicolumn{2}{|c|}{$d^{\prime}$ scores } & \multicolumn{2}{|c|}{$C$ scores } & \multicolumn{2}{|c|}{$d^{\prime}$ scores } & \multicolumn{2}{|c|}{$C$ scores } \\
\hline & One & Two & One & Two & One & Two & One & Two \\
\hline Young & -.07 & +.15 & +.10 & -.37 & $-.46^{*}$ & +.24 & -.36 & -.19 \\
\hline Elderly & $-.54 *$ & -.04 & -.07 & +.29 & -.40 & $+.58 \dagger$ & -.17 & -.22 \\
\hline All subjects & $-.37^{*}$ & +.03 & -.01 & -.09 & $-.42 \dagger$ & $+.47 \dagger$ & -.24 & -.21 \\
\hline
\end{tabular}

Note-Row 3 contains partial correlations with subject age removed. There were 19 young and 20 elderly subjects, so $d f$ s were 17,18 , and 36 for Rows 1,2 , and 3 , respectively. ${ }^{*} p<05$. $\dagger p<.01$.

recall. Thus, the age $\times$ presentations interaction in subjects' $C$ scores (Figure 3 ) appears not to be attributable to verbal-memory deficits. ${ }^{6}$

\section{Discussion}

Experiment 1 was conducted to test the idea that elderly subjects differ from young-adult subjects in relying relatively more on perceived resemblance (familiarity) and relatively less on recollection of context, in making recognition decisions. This context-recollection hypothesis predicts that prior presentations of the lures in a test should increase the age difference in false alarms to these lures. This pattern was confirmed, though the relevant interaction was statistically significant only in a planned comparison of zero-presented (entirely new) lures with twicepresented lures. However, additional analyses of hits and false alarms revealed that the elderly subjects made significantly more correct and erroneous seen-today judgments in response to twice-presented items as opposed to once-presented items (Figure 2) and showed significantly lower criteria for making seen-today judgments for twicepresented items as opposed to once-presented items (Figure 3). If we assume that repetition increased the perception of resemblance (familiarity), these data suggest that elderly subjects but not young adults made seen-today judgments primarily on the basis of resemblance information.

Since we are interpreting the data on recognition criteria in a nonstandard way, some additional comments are in order. Note that measures of criterion in signal detection theory reflect the location of a recognition criterion relative to the noise and signal-plus-noise distributions. It follows that if both noise and signal-plus-noise distributions are shifted up along a resemblance (familiarity) continuum, so that greater portions of both distributions fall beyond the recognition criterion, this might appear as a lowered criterion (i.e., as a more lax criterion for recognition judgments). Such an upward shift in both distributions is what we expect if both recent items (signals) and nonrecent items (noise) are presented twice at input.

However, a shift in the noise and signal-plus-noise distributions should cause a reduction in a measure of criterion only if subjects are making their recognition decisions primarily on the basis of resemblance information.
To the extent that this is not the case, and that subjects are making their recognition judgments on some other basis such as recollection of context, the effect of a shift in distributions will be masked. In light of the foregoing, the context-recollection hypothesis implies that repetition should reduce criterion levels among the elderly subjects (who recognize faces on the basis of perceived resemblance), but not among the young subjects (who make greater use of recollection of context). This was precisely the pattern that was observed.

The signal detection analysis is useful not only for supporting the context-recollection hypothesis, but for refuting the competing hypothesis that older subjects function with loosened criteria as a compensating strategy for their processing deficits. The obvious difficulty for this compensation hypothesis is that the elderly differed from the young-adult subjects not simply in having more lax criteria, but in showing an effect of prior-presentations on criteria. Without elaboration, a compensation hypothesis cannot explain this interactive pattern.

Another useful finding from Experiment 1 concerned the recognition and familiarity ratings made in the input task (Table 2). Despite an age-related increase in false recognitions, there was no apparent tendency for the elderly subjects to rate input faces as more familiar to them. This finding is important, because it contradicts the otherwise plausible notion of an age-related increase in signals of resemblance evoked by new faces. To save this familiarity hypothesis, it might be argued that older persons use more stringent criteria for judging faces to be familiar. However, if the elderly use more stringent criteria, how can we explain the original finding of an agerelated increase in false-alarm errors (replicated here in both input lists)? Note, in addition, that the familiarity hypothesis fails where the compensation hypothesis fails; it does not explain the effects of repetition on older subjects' today judgments and $C$ scores.

An unexpected finding of Experiment 1 was that the elderly subjects made fewer last-week judgments than did younger subjects (Figure 1). Not only were they lower in correct last-week judgments, they were lower in erroneous last-week judgments as well. This might imply that the mnemonic information used by older subjects (resemblance information?) is essentially atemporal, lead- 
ing to impressions of recent occurrence, or of complete newness, but seldom to impressions of a prior experience in the somewhat distant past. In any event, the age-related decrease in last-week judgments suggests age-related differences in the phenomenal experience of recollecting the past (Tulving, 1983).

In summary, the data from Experiment 1 supported the context-recollection hypothesis while posing serious problems for alternative hypotheses. However, these data were collected in a somewhat unusual recognition task, a task demanding judgments of recency. Since judgments of recency might be based on different processes than judgments of other attributes of faces, the theoretical implications of Experiment 1 might not be generalizable. To address this issue, in Experiment 2 we employed a more standard type of recognition task, one demanding judgments of whether or not faces were famous.

\section{EXPERIMENT 2}

The design of this experiment was based on a study of verbal recognition memory by Jacoby, Woloshyn, and Kelly (1989; see also Jacoby, Kelly, \& Dywan, 1989). Using proper names as stimuli, Jacoby and colleagues examined famous versus nonfamous judgments of names of famous persons, nonfamous names encountered earlier in the experiment, and nonfamous names that had not been seen before. They found that false famous judgments in response to previously viewed names were sometimes more frequent than those to new names, and sometimes less frequent than those to new names, depending upon the testing conditions. The authors argued that the outcome depended on whether perceived familiarity or analytical knowledge of presentation context was the primary basis for recognition decisions: The use of familiarity information produced more false famous judgments in response to previously viewed names, whereas the use of analytical knowledge produced fewer false famous judgments in response to previously viewed names. Our goal in Experiment 2 was to extend the method of Jacoby, Woloshyn, and Kelly (1989) by using faces instead of names, with a sample of elderly subjects as well as a sample of young adults.

Our thinking was as follows: If older subjects recognize faces primarily on the basis of perceived familiarity (resemblance information), they should show a false fame effect (i.e., they should make more false famous judgments of previously viewed faces). If young-adult subjects place greater reliance on recollection of contextual information, they should show no such effect or, perhaps, the opposite effect. In either case, the age-related increase in false famous judgments should be stronger in response to previously viewed faces than to entirely new faces.

\section{Method}

This experiment was conducted simultaneously with Experiment 1 , with the same subjects. The procedure consisted of two phases, an input phase in which a list of nonfamous faces was presented and a test phase that required judgments of fame (see Table 1).

Materials. The stimulus faces that were used in this study were selected from a large set of famous and nonfamous faces rephotographed from an assortment of magazines of wide and narrow circulation. On the basis of two rounds of pilot testing, we eliminated famous faces that would probably have been recognized by all subjects (producing ceiling effects), as well as those recognized by fewer than $50 \%$ of a group of intelligent adults. The pilot testing confirmed our intuitive expectation that young adults would exceed elderly adults in recognizing the young-famous faces though not the elderly-famous faces. This was not a significant cause for concern, since our focus was on the false-alarm errors.

The final set of faces included 48 famous faces of entertainers (30), politicians (10), sports figures (4), religious leaders (2), and business leaders (2), as well as $\mathbf{4 8}$ nonfamous faces of unknown business persons (17), professional and nonprofessional models appearing in advertisement pictures (17), citizens participating in activities or events reported in minor news stories (10), and friends or relatives of famous individuals (4). Within each set of 48 faces, there were 8 young males and 8 young females $20-39$ years old, 8 middle-aged males and 8 middle-aged females $40-59$ years old, and 8 elderly males and 8 elderly females 59 years old and over. All pictures of faces were transferred onto optical disk and recorded in black and white on Super-VHS videotape as in Experiment 1.

The input list presented in Session 1 included 32 of the 48 nonfamous faces that subsequently appeared in the fame-judgment task. Half of the critical 32 faces were repeated after a lag of 4-6 intervening faces. Thus the entire list included 48 pictures of faces, along with 1 filler face picture at the start of the list and 2 filler face pictures at the end. Three different versions of the input list were used with approximately equal numbers of young and elderly subjects. The three lists were varied so that the once-presented faces in one list were the twice-presented faces in a second list and were not shown at all in a third list.

The recognition test of Session 2 was a randomized sequence of all 48 nonfamous faces intermixed with 48 famous faces. It was the same for all subjects.

Procedure. Before presentation of the input list in Session 1, the subjects were told that they would see a set of pictures of nonfamous faces taken from magazines. The task was the same as in Experiment 1: The subjects were asked to identify repeated faces and rate the familiarity of all nonrepeated faces. Following these instructions, the input list was presented, with each face picture shown for $7 \mathrm{sec}$ and followed by a 3-sec interstimulus interval.

Prior to the test, which occurred in Session 2, the subjects were told that they would see another list of faces, but that some of these faces would be of famous persons, including entertainers, newspersons, politicians, sports personalities, and television and movie actors and actresses. The task was to judge each face as being definitely famous, possibly famous, or nonfamous, using a 3-point scale $(3=$ definitely famous). The criterion for the highest rating was verbal knowledge of the person's name or the context of prior experience (e.g., a television program). However, we did not ask the subjects to produce their knowledge of the name or context explicitly.

The instructions stated that any face seen in the prior week's session could be assumed to be nonfamous. Thus, subjects were told that if a face was recognized to be from the prior input list, it should be judged as nonfamous ( 1 on the 3-point scale).

\section{Results}

Familiarity and recognition judgments at input. Table 2 reveals that recognition hit rates were at or near the ceiling; recognition false-alarm rates showed an age- 
related increase; and familiarity ratings did not show an age difference. These results closely matched those from the first input session of Experiment 1.

Famous judgments at test. The subjects responded to each test face with a three-level judgment of sure famous, possibly famous, or nonfamous. It therefore was possible to compute hit rates and false-alarm rates at two criterion levels, strict (proportions of sure-famous judgments) and lax (proportions of sure-famous judgments plus possibly famous judgments). A preliminary look at the strict-criterion scores revealed that floor effects were present with the false-alarm rates. For this reason, the hit and false-alarm rates reported subsequently in this section will be those derived from lax-criterion scoring. ${ }^{7}$

An ANOVA performed on hit rates for responses to famous faces showed a main effect of face age $[F(2,74)=$ $20.3, M S_{\mathrm{e}}=.009$ ]. The effect of subject age was only marginally reliable $\left[F(1,37)=3.85, M S_{\mathrm{e}}=.047\right.$, $p<.06$, but the subject age $\times$ face age interaction was clearly significant $\left[F(2,74)=19.0, M S_{\mathrm{e}}=.009\right]$. As is shown in Figure 4 (see the two upper functions), the age difference was reliable with respect to young faces $\left[F(1,37)=13.9, M S_{\mathrm{e}}=.028\right]$ and middle-aged faces $\left[F(1,37)=6.88, M S_{\mathrm{e}}=.013\right]$, but not elderly faces.

An ANOVA performed on the false-alarm rates produced a different pattern of effects. The effect of subject age was highly reliable $\left[F(1,37)=41.8, M S_{e}=.150\right]$, but no effects involving face age were statistically significant. As is shown in Figure 4 (see the two lower functions), the elderly were higher in false-alarm rates regardless of face age.

The most important result of the false-alarm rate ANOVA was a significant prior presentations $\times$ age interaction $\left[F(2,74)=4.41, M S_{\mathrm{c}}=.050\right]$. As is shown in Figure 5, the age-related increase in false-alarm rates increased with prior presentations. The interaction remained

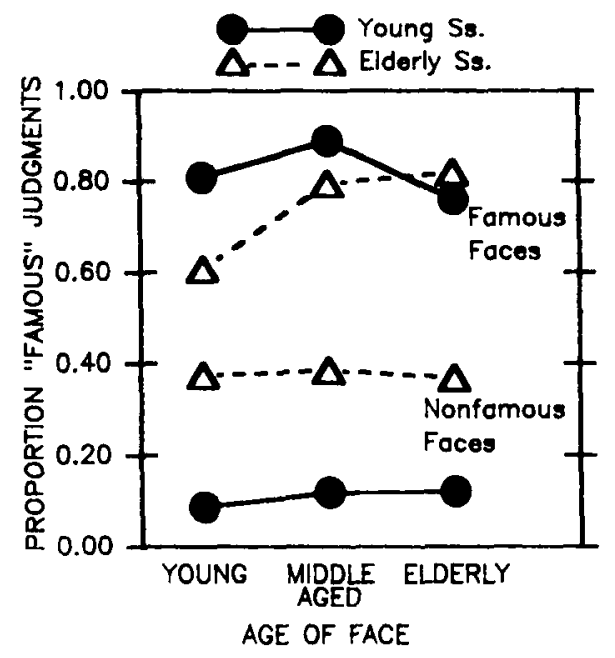

Figure 4. Proportions of famous judgments in response to famous faces (hits) and nonfamous faces (false alarms) as a function of faceage among young and elderly subjects in Experiment 2.

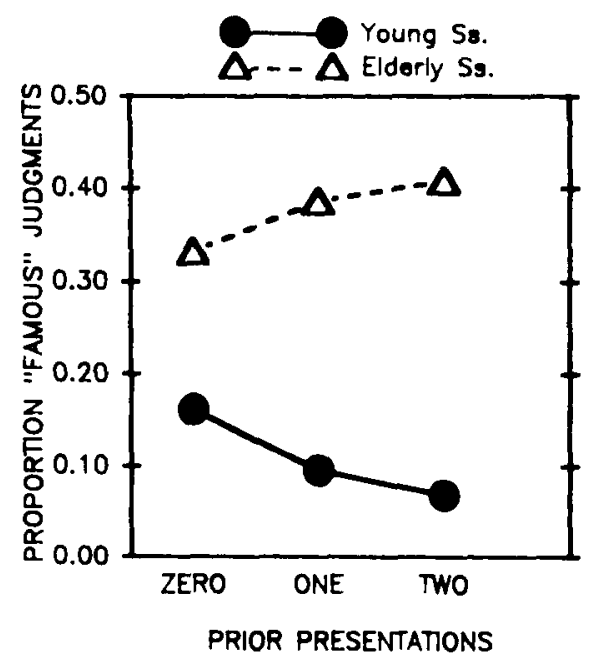

Figure 5. Proportions of famous judgments in response to nonfamous faces (false alarms) as a function of number of prior presentations among young and elderly subjects in Experiment 2 .

reliable in contrasts between zero-presented (new) items and once-presented items $\left[F(1,37)=4.75, M S_{e}=.043\right]$, as well as new items and twice-presented items $[F(1,37)=$ $\left.5.71, M S_{\mathrm{e}}=.073\right]$. However, there was no prior presentations $\times$ age interaction in a contrast between once- and twice-presented items $\left[F(1,37)=1.1, M S_{\mathrm{e}}=.033, p>\right.$ .20]. The $\omega^{2}$ measure showed that age accounted for $17 \%$ of the between-subjects variance in false recognitions of entirely new items and $49 \%$ of the between-subjects variance with both once-presented and twice-presented items.

Relations to verbal-memory performance. We again performed a correlational analysis, this time focusing on how paired-associates and paragraph recall were linked to false recognitions of nonfamous faces shown zero, one, or two times at input. As is shown in Table 4, the correlations between these false recognitions and the verbalmemory measures were generally small and nonsignificant. The single exception (a Type I error?) was a negative correlation $(r=-.52)$ between paragraph-recall and false-alarm errors in response to twice-presented faces in the young-adult group.

\section{GENERAL DISCUSSION}

The point of departure for this investigation was that elderly adults exceed young adults in false-alarm errors in response to new faces. One account of this finding is that elderly subjects base their recognition decisions relatively more on perceived resemblance (familiarity), and relatively less on conscious recollection of contextual information, than do young adults. This context-recollection hypothesis predicts that the age-related differences in false-alarm errors will grow larger as faces become more familiar. This prediction was supported in two different studies, the first on recognition of recency and the second on recognition of fame. Both of these studies repli- 
Table 4

Pearson Product-Moment Correlations between Verbal-Memory Measures and False Famous Judgments in Response to Nonfamous Faces Seen Zero, One, or Two Times at Input in Experiment 2

\begin{tabular}{|c|c|c|c|c|c|c|}
\hline \multirow[b]{2}{*}{ Age Group } & \multicolumn{3}{|c|}{$\begin{array}{c}\text { Paired-Associates } \\
\text { Recall }\end{array}$} & \multicolumn{3}{|c|}{ Paragraph Recall } \\
\hline & Zero & One & Two & Zero & One & Two \\
\hline Young & -.07 & +.00 & -.09 & -.05 & -.26 & -.5 \\
\hline Elderly & +.10 & +.29 & -.36 & +.25 & +.30 & +.07 \\
\hline All subjects & +.03 & +.21 & -.28 & +.13 & +.17 & -.09 \\
\hline
\end{tabular}

Note-Row 3 contains partial correlations with subject age removed. There were 19 young and 20 elderly subjects, so $d f s$ were 17,18 , and 36 for Rows 1, 2, and 3, respectively. ${ }^{*} p<.05$.

cated the finding of age-related increases in false-alarm errors (false judgments of recency and false judgments of fame). Moreover, both studies showed that these agerelated increases were strengthened by the prior presentation of lures. The statistical support for this conclusion was admittedly weaker in Experiment 1 than in Experiment 2. However, a noteworthy finding in Experiment 1 was that the criterion for judging that faces were recent was significantly reduced by repetition at input, but only among the elderly subjects. On the assumption that repetition increased resemblance information, this finding suggests that resemblance information was a more important basis for recency judgments in the elderly group than in the young-adult group. This is consistent with the contextrecollection hypothesis.

In supporting the context-recollection hypothesis, the data posed problems for two otherwise plausible hypotheses for age-related differences in false recognition of faces. The compensation hypothesis held that elderly subjects have adopted the compensating strategy of recognizing faces on the basis of relatively low levels of resemblance information (i.e., loose criteria). The resemblance hypothesis held that entirely new faces are perceived as more familiar (or as higher in resemblance) by older individuals than by younger individuals. Either hypothesis could have predicted the finding that elderly subjects would exceed younger subjects in false recent judgments as well as false famous judgments of lure faces in a test. However, neither hypothesis can handle the finding that these age-related increases in false-alarm errors were increased by prior presentation of lures (Figures 2 and 5). In addition, the compensation hypothesis fails to explain why age-related reductions in recognition criteria were larger for twice-presented faces than for once-presented faces (Figure 3). Finally, the resemblance hypothesis was directly contradicted by subjects' familiarity ratings during presentation of the input lists (Table 2).

Support for the context-recollection hypothesis derives not only from face-memory studies, but from verbalmemory studies as well. For example, in a recent investigation, Dywan and Jacoby (1990) examined age-related differences in judgments of fame by using proper names rather than faces as stimuli. Except for the use of names rather than faces, the design resembled that of the present Experiment 2 (which was based on other work described in Jacoby, Kelly, \& Dywan, 1989). And the results of the study were similar as well: As in the present Experiment 2, Dywan and Jacoby (1990) found that prior presentation of nonfamous names tended to increase false alarms among elderly subjects, and to reduce false alarms among young-adult subjects, producing an age $\times$ prior presentation interaction.

Beyond the realm of memory for faces and names, the context-recollection hypothesis is broadly consistent with accumulating evidence that the elderly are deficient in memory for source. Several ingenious studies have shown that although elderly adults have fairly good memory for information encoded in experimental tasks, they fall below young adults in remembering (1) that they encoded the information in the experimental task (McIntyre \& Craik, 1987), (2) whether they encoded the information through performance, imagination, or action (Cohen \& Faulkner, 1989), and (3) in which of two voices the information was presented (Hashtroudi, Johnson, \& Chrosniak, 1989). Although there have been some instances in which memory for source did not show age differences (Hashtroudi et al., 1989), the available data suggest that the recollection of details about the context of learning poses disproportionate problems for elderly subjects. This, of course, is entirely consistent with the context-recollection hypothesis as it is formulated here.

Notwithstanding this evidence that age-related differences in recollecting context may extend from faces to other types of stimuli, faces probably differ from (some) other types of stimuli with respect to age differences. In our introduction, we noted that false-alarm errors in response to entirely new items show consistent age differences in face recognition, but inconsistent age differences in word and (nonfacial) picture recognition. The previously cited study by Dywan and Jacoby (1990) reinforces this point. Their study of famous-name recognition showed an age $\times$ prior presentations interaction similar to that of Experiment 2. However, they did not observe that the elderly subjects exceeded the young in false-alarm errors in response to entirely new lures as in Experiment 2 and other face-recognition studies. $\mathrm{Al}-$ though caution is required in making comparisons between the Dywan and Jacoby study and the present investigation, their findings are consistent with several other studies of verbal recognition memory in which age-related increases in false-alarm errors have often been absent or unreliable. We clearly need careful comparisons of agerelated differences in recognition memory for different classes of stimulus materials, including faces and names. If it is true that age differences in false-alarm errors are more robust with faces than with other types of stimuli, we will need research on why this is so.

Apart from questions about stimulus effects, the findings presented in this report have applied implications for eyewitness identification. Indeed, our findings converge with research by Yarmey (1984), who found age-related deficits in correct rejections of innocent suspects from simulations of line-ups. As one would expect on the basis of the present findings, the age-related deficits that Yar- 
mey observed were larger when the suspects had been previously seen (i.e., when they were innocent bystanders at the scene of the crime) than when they had not (i.e., when they were entirely new persons). In that the rate of rejecting innocent suspects is the inverse of the falsealarm rate, the accumulated data tell a consistent story: They show that age-related differences in false-alarm rates are generally present, but these age-related differences are increased to the extent that the recognition lures are familiar to the subjects. Indeed, the context-recollection hypothesis developed in this paper could have predicted Yarmey's finding.

From an applied perspective, an important direction for future research is to examine what kinds of conditions of testing might reduce the effects of resemblance information in identifying suspects. The recent literature on eyewitness identification (e.g., Lindsay \& Wells, 1985) describes some promising techniques that warrant thorough testing with elderly subjects. Encouragingly, a recent verbal-memory study (Masson, Carroll, \& Micco, 1990) has shown that it is possible to induce older subjects to forego the use of resemblance information in making recognition judgments. Research on this issue, using facial materials as well as naturalistic testing conditions, clearly would be timely.

In closing this paper, we consider whether age differences in face recognition pertain to the normal aging of memory, or to the pathological aging of memory as seen in the dementias. What little evidence we have on this issue suggests that age differences in face recognition occur in normal elderly groups that are free of obvious pathology. First, Ferris et al. (1980) found nearly identical face-recognition performance in a normal-elderly group (with Guild test scores at or above the means for their age and vocabulary levels) and an elderly-demented group (with Guild test scores at least $1 S D$ below the means for their age and vocabulary levels). Moreover, both of these groups of elderly subjects showed increased false alarms, in comparison with young adults. Second, though the present studies' measures of verbal-recall memory showed age-related deficits, they were largely uncorrelated with the face-recognition measures showing qualitative differences between young and older subjects (e.g., $C$ scores in Experiment 1). Of course, some subset of our elderly subjects may have been suffering from undetected dementia (Rissenberg \& Glanzer, 1986). However, if there were very many of these individuals, and if dementia is related to both verbal-recall memory and face recognition, we might have expected somewhat stronger correlations between the verbal-memory measures and face-recognition measures among the older subjects.

\section{REFERENCES}

Bartlett, J. C., Gernsbacher, M. A., \& Till, R. E. (1987). Remembering left-right orientation of pictures. Journal of Experimental Psychology: Learning, Memory, \& Cognition, 13, 27-35.

Bartlett, J. C., Hurry, S., \& Thorley, W. (1984). Typicality and familiarity of faces. Memory \& Cognition, 12, 219-228.
Bartlett, J. C., \& Leslie, J. E. (1986). Aging and memory for faces versus single views of faces. Memory \& Cognition, 14, 371-381.

Bartlett, J. C., Leslie, J. E., Tubbs, A., \& Fulton, A. (1989). Aging and memory for pictures of faces. Psychology \& Aging, 4, 276-283.

BruCE, V. (1988). Recognizing faces. Hillsdale, NJ: Erlbaum.

BRUCE, V., \& YounG, A. W. (1986). Understanding face recognition. British Journal of Psychology, 77, 305-327.

CoHEN, G., FAULKNER, D. (1989). Age differences in source forgetting: Effects on reality monitoring and on eyewitness testimony. Psychology \& Aging, 4, 10-17.

CraIK, F. I. M. (1989). On the making of episodes. In H. L. Roediger III \& F. I. M. Craik (Eds.), Varieties of memory and consciousness: Essays in honour of Endel Tulving (pp. 43-58). Hillsdale, NJ: Erlbaum.

Craik, F. I. M., \& MCDowD, J. M. (1987). Age differences in recall and recognition. Journal of Experimental Psychology: Learning. Memory, \& Cognition, 13, 474-479

Davies, G. M., Shepherd, J. W. Ellis, H. D. (1979). Similarity effects in face recognition. American Journal of Psychology, 92, 507-523.

Diamond, R. C CAREY, S. (1986). Why faces are and are not special: An effect of expertise. Journal of Experimental Psychology: General, 115, 107-117.

DYWAN, J., JACOBY, L. (1990). Effects of aging on source monitoring: Differences in susceptibility to false fame. Psychology \& Aging, 5, 379-387

Ferrus, S. H., Crook, T., Clark, E., McCarthy, M., Rae, D (1980). Facial recognition memory deficits in normal aging and dementia. Joumal of Gerontology, 35, 707-714.

Fuin, R., \& Dziurawiec, S. (1989). Developmental factors in face processing. In A. W. Young \& H. D. Ellis (Eds.), Handbook of research on face processing (pp. 335-378). New York: Elsevier North-Holland.

Gilbert, J. G., Levee, R. F., \& Catalano, F. L. (1974). Guild memory test manual. Newark, NJ: UNICO National Mental Health Research Foundation.

Gillund, G., \& ShIfFrin, R. M. (1984). A retrieval model for both recognition and recall. Psychological Review, 91, 1-67.

Goldstein, A. G., Stephenson, B., \& Chance, J. (1977). Face recognition memory: Distribution of false alarms. Bulletin of the Psychonomic Society, 9, 416-418.

Harkins, S. W., Chapman, C. R., \& Eisdorfer, C. (1979). Memory loss and response bias in senescence. Journal of Gerontology, 34, 66-72.

Hashtroudi, S., Johnson, M. K., \& Chrosniak, L. (1989). Aging and source monitoring. Psychology \& Aging, 4, 106-112.

HAY, D. C., \& Young, A. W. (1982). The human face. In A. W. Ellis (Ed.), Normality and pathology in cognitive functions (pp. 173-202). New York: Academic Press

Hess, T. M. (1984). Effects of semantically related and unrelated contexts on recognition memory of different-aged adults. Joumal of Gerontology, 39, 444-451.

Hess, T. M., \& Higgins, J. N. (1983). Context utilization in young and old adults. Journal of Gerontology, 38, 65-71.

Huppert, F. A., \& Piercy, M. (1978). The role of trace strength in recency and frequency judgments by amnesic and control subjects. Quarterly Journal of Experimental Psychology, 30, 347-354.

JaCOBY, L. L., Kelly, C. M., \& DYWAN, J. (1989). Memory attributions. In H. L. Roediger III \& F. I. M. Craik (Eds.), Varieties of memory and consciousness: Essays in honour of Endel Tulving (pp. 391-420). Hillsdale, NJ: Erlbaum.

JACOBY, L. L., Woloshyn, V., \& Kelly, C. M. (1989). Becoming famous without being recognized: Unconscious influences on memory produced by dividing attention. Journal of Experimental Psychology: General, 118, 115-125.

Light, L. L., ANDERSON, P. A. (1983). Memory for scripts in young and older adults. Memory \& Cognition, 11, 435-444.

LindSAY, R. C., \& WelLS, G. L. (1985). Improving eyewitness identifications from lineups: Simultaneous versus sequential lineup presentation. Journal of Applied Psychology, 70, 556-564.

LIST, J. A. (1986). Age and schematic differences in the reliability of eyewitness testimony. Developmental Psychology, 22, 50-57. 
MANDLER, G. (1980). Recognizing: The judgment of previous occurrence. Psychological Review, 87, 252-271.

Masson, M. E. J., Carroll, M., \& Micco, A. (1990). Age-related differences in attributions of fluency. Manuscript submitted for publication.

MCINTYRE, J. S., \& Craik, F. I. M. (1987). Age differences for item and source information. Canadian Joumal of Psychology, 41, 175-192.

PARK, D. C., \&uglisi, J. T. (1985). Older adults' memory for the color of pictures and words. Journal of Gerontology, 40, 198-204.

Park, D. C., Puglisi, J. T., \& Smith, A. D. (1986). Memory for pictures: Does an age-related decline exist? Journal of Psychology \& Aging, 1, 11-17.

RABINOWITZ, J. C. (1984). Aging and recognition failure. Journal of Gerontology, 39, 65-71.

RANkin, J. L., \& KAUSLER, D. H. (1979). Adult age differences in false recognitions. Journal of Gerontology, 34, 58-65.

Reder, L. M., Wible, C., MARTIN, J. (1986). Differential memory changes with age: Exact retrieval versus plausible inference. Journal of Experimental Psychology: Learning, Memory, \& Cognition, 12 , 72-81.

RissenberG, M., \& Glanzer, M. (1986). The effects of normal aging and primary degenerative dementia. Journal of Gerontology, 41, 64-71.

Smith, A. D. (1975). Partial learning and recognition memory in the aged. International Journal of Aging \& Human Development, 6 , 359-365.

SMith, A. D., \& Winograd, E. (1978). Adult age differences in remembering faces. Developmental Psychology, 14, 443-444.

SNodgrass, J. G., \& CoRwIN, J. (1988). Pragmatics of measuring recognition memory: Applications to dementia and amnesia. Joumal of Experimental Psychology: General, 117, 34-50.

Tulving, E. (1983). Elements of episodic memory. New York: Oxford University Press.

WINOGRAD, E. (1981). Elaboration and distinctiveness in memory for faces. Journal of Experimental Psychology: Learning, Memory, \& Cognition, 7, 181-190.

YARMEY, A. D. (1984). Age as a factor in eyewitness testimony. In G. L. Wells \& E. F. Loftus (Eds.), Eyewitness testimony (pp. 142154). New York: Cambridge University Press.

YounG, A. W., \& EluIs, H. W. (1989). Semantic processing. In A. W. Young \& H. D. Ellis (Eds.), Handbook of research on face processing (pp. 235-262). New York: Elsevier North-Holland.

Young, A. W., Hay, D. C., Ellis, A. W. (1985). The faces that launched a thousand slips: Everyday difficulties and errors in recognizing people. British Journal of Psychology, 76, 495-523.

\section{NOTES}

1. We previously found reduced age differences in recognition accuracy (i.e., $A^{\prime}$ scores) when subjects were allowed to see input faces as they do in real life-that is, in multiple views with varied poses and expressions (Bartlett \& Leslie, 1986). However, erroneous old judgments in response to new faces were consistently higher in the elderly groups, even with multiview presentation (see Table 2 of Bartlett \& Leslie, 1986).

2. The outcomes of the analyses of variance were substantially unchanged when these 3 subjects were dropped and also when acuity was used as a covariate.

3. In the ANOVA of today judgments, as well as the ANOVA of $d^{\prime}$ and $C$ scores, face age was included as a within-subjects factor. Although this variable had main effects, it did not interact with subject age, and we will not discuss it further.

4. We computed $d^{\prime}$ and $C$ scores as in Snodgrass and Corwin (1988). Like the better known $\beta$ measure, $C$ scores vary from -1.00 (the most lax criterion) to +1.00 (the most stringent criterion). Accuracy and bias measures from two-threshold theory ( $\mathrm{Pr}$ and $\mathrm{Br}$ scores) produced the same outcome as that in Figure 3.

5. Because of the group-testing method as well as limits on time, the procedures of the Guild test could not be precisely followed. This precluded comparison of the subjects' performance to the published norms for this test.

6. The correlations in Table 3 suggest that subjects with higher verbalmemory scores showed larger improvements in $d^{\prime}$ scores between oncepresented faces and twice-presented faces. Indeed, difference scores indexing the degree of improvement from once- to twice-presented items were positively correlated with paragraph recall $(r \mathrm{~s}=.42, .72$, and .62 for young subjects, elderly subjects, and both age groups together with age removed; $d f s=17,18$, and 36 , and $p s<.10, .05$, and .01 , respectively). In contrast, these difference scores were unrelated to age $(r=.08)$. It appears that the learning of temporal information as a result of repetition was related to verbal-memory ability but unrelated to age.

7. Despite floor effects, the findings obtained with strict-criterion scoring resembled those reported in this section. Specifically, strict-criterion hit rates showed significant main effects of subject age and face age as well as a subject age $\times$ face age interaction. The pattern was similar to that in Figure 4 (see the upper two functions), except that the subjectage effect appeared to be stronger with younger faces. The strict-criterion false-alarm rates showed significant main effects for both subject age and prior presentations, and the prior presentations $\times$ age interaction (Figure 5) was marginally significant $\left[F(2,74)=2.97, M S_{\mathrm{e}}=.011\right.$, $p<.06]$. The proportions of sure-famous judgments in the young-adult group averaged $.01, .02$, and .01 for zero, one, and two presentations, respectively $(F<1)$. The comparable proportions in the elderly group averaged $.05, .08$, and .12 , respectively $\left[F(2,38)=3.52, M S_{\mathrm{e}}=.021\right.$, $p<.05]$
(Manuscript received June 4, 1990; revision accepted for publication September 17, 1990.)

\title{
Announcement
}

\author{
Fifth Toledo Symposium on Advances in Biobehavioral Research \\ Mechanisms and Models of Interhemispheric Communication \\ University of Toledo, Driscoll Center \\ April 12-13, 1991
}

This symposium will present advances in theory, models, techniques, and research which characterize the nature of interhemispheric communication. The participants will be: M. Banich, D. Boles, C. Chiarello, S. Christman, R. Gur, C. Hamilton, C. Hardyck, L. Harris, J. Hellige, S. Levine, J. Liederman, L. Robertson, J. Sergent, S. Witleson, and E. Zaibel.

For further information, call F. Kitterle at $419-537-2722$ or on E-mail FAC0532@UOFT01. 